\title{
Impact of Job Status on Accessibility of Cancer Screening
}

\section{Seung Ju Kim, $\mathrm{RN}^{1,2}$ \\ Kyu-Tae Han ${ }^{12}$ \\ Eun-Cheol Park, MD, PhD2,3}

${ }^{1}$ Department of Public Health,

Graduate School, Yonsei University, Seoul,

${ }^{2}$ Institute of Health Services Research,

Yonsei University, Seoul,

${ }^{3}$ Department of Preventive Medicine,

Yonsei University College of Medicine, Seoul, Korea
Correspondence: Eun-Cheol Park, MD, PhD

Department of Preventive Medicine,

Yonsei University College of Medicine,

50 Yonsei-ro, Seodaemun-gu, Seoul 03722, Korea

Tel: 82-2-2228-1862

Fax: 82-2-392-8133

E-mail: ecpark@yuhs.ac

Received February 2, 2015

Accepted May 28, 2015

Published Online July 14, 2015

\section{Purpose}

Cancer is a leading cause of death worldwide with approximately 75,000 cancer deaths in Korea alone in 2013. Cancer screening is an important method of prevention; however, only $63.4 \%$ of Koreans sought cancer screening in 2012 even though it was widely offered at no cost. We focused on part time workers because they often experience job instability and relative discrimination. Therefore, we investigated the correlation between job status and cancer screening.

\section{Materials and Methods}

Data from the 2013 Korea National Health and Nutrition Examination Survey (KNHANES) were used for selection of individuals who participated in the national cancer screening program. A total of 1,326 wage earners were selected for our study. The association between cancer screening and part time job status was examined using logistic regression models.

\section{Results}

Of the 1,326 individuals selected for the study, 869 (64.5\%) had participated in the cancer screening program; among these, 421 (48.4\%) were part time workers and 448 (51.6\%) were full time workers. Lower prevalence of cancer screening was observed for part time workers compared to full time workers (odds ratio, 0.72; confidence interval, 0.53 to 1.00; $p=0.0495$ ). Factors including age, marital status, private insurance, chronic disease, smoking, and residential area emerged as showed significant association with participation in screening programs.

\section{Conclusion}

We found that part time workers had difficulty participating in prevention programs. Change in the workplace environment as well as development of positive social programs targeted to part time workers is necessary in order to encourage participation of part time workers in prevention programs.

\section{Introduction}

Chronic disease is a major public health problem; cancer, in particular, has increased the global burden of disease as well as mortality. It has been estimated that cancer was responsible for approximately 8.2 million cancer deaths

\section{Key words}

Early detection of cancer, Health promotion, Employment, Occupational health 
types of cancer $[4,5]$. Thus, cancer screening programs have been introduced in many countries.

In Korea, cancer is a leading cause of death, where the rate of mortality increased from 131.1 per 100,000 individuals in 2003 to 149.0 per 100,000 individuals in 2013 [6]. To reduce the mortality rate, the government instituted a cancer control program through the National Cancer Center, which involves registration, screening, and management of cancer patients as well as patient education $[7,8]$. Cancer screening is provided as a means of early detection, without cost, according to specific age group and type of cancer (stomach, liver, colon, breast, cervical cancer). Although the rate of total cancer screening increased from $45.6 \%$ in 2007 to $63.4 \%$ in 2012 as a result of this program, the rate was still lower than that reported for other developed countries [9]. Furthermore, while the national cancer screening program was provided by the government free of charge, the proportion of the population eligible for cancer screening was below $50 \%$; therefore, better management of programs for early detection of cancer is necessary.

We focused on job status such as part time versus full time employment as a factor that can affect whether individuals seek cancer screening. Compared to stable, full time workers, those with part time employment might be less likely to manage self-care as well as take steps to improve their health. Compared to workers with full time jobs, part time workers are faced with the threat of job loss, lower wages, an unstable employment state, as well as less power [10].

In Korea in 2014, 6 million people were employed on a part time basis. Due to the lack of job security, this population experiences discrimination and anxiety which impacts health management. Previous studies explored the association between lack of job security and poor health $[11,12]$. In addition, the association between cancer screening and personal factors has been investigated, while few studies on cancer screening in relation to job status specifically have been reported $[13,14]$. Especially in Korea, where the proportion of part time workers is high, there is a great need for better health management in this population.

Thus, the aim of our study was to examine the association between job status and likelihood of participating in cancer screening programs, comparing part time and full time workers in Korea. In addition, the results were analyzed according to age group, residential area, and work type.

\section{Materials and Methods}

\section{Data and study population}

Our study used data from the sixth edition of the Korea National Health and Nutrition Examination Survey (KNHANES, 2013) conducted by the Korea Centers for Disease Control and Prevention. This survey is conducted annually and received its most recent Institutional Review Board (IRB) approval from the Korea Centers for Disease Control and Prevention in 2013 (2013-07CON-03-4C). General information on individuals including education, economic activity, nutrition, and health behaviors, including alcohol consumption, was obtained by self-report. From these data, cancer patients $(\mathrm{n}=50)$ and unemployed individuals $(\mathrm{n}=5,856)$, independent businessmen, and employers were excluded; thus, only wage earners were included in our study. Next, we included participants who applied for the national cancer screening program. Because the national cancer screening program is applied differently by sex, we selected female subjects over 30 years of age and male subjects over 40 years of age. Cervical cancer screening was initiated at age 30 for females, and liver, colon, and stomach cancer screening were initiated at age 40 in both males and females. In this proceeding, female participants $(n=224)$ and male participants $(n=455)$ were excluded, due to unsuitable age. Participants were included until age 69 as working persons ( $\mathrm{n}=77$ excluded). Finally, missing value was excluded $(n=30)$. A total of 1,326 participants were eligible for this study (Fig. 1).

\section{Cancer screening and job status}

Cancer screening was measured based on self-reported answers to the following question: "Have you undergone cancer screening in the last 2 years?" where cancer screening was classified as those who underwent cancer screening and those who did not.

Job status was classified with the following the question: "Are you working in a full time or part time position currently?" A full time worker was defined as a person who was guaranteed employment until retirement age. A part time worker was defined as a person whose job was temporary, atypical, or short-term.

Work type was determined by answers to the questions, "Do you mainly work in the daytime (6:00 AM to 6:00 PM), night time (2:00 PM to 12:00 PM or 9:00 PM to 08:00 AM), or different time shifts (irregular shifts)?"

Office hours worked per week were measured with the following question: "How much time do you spend working in a workplace during a 1-week period, including overtime?" Hours worked excluded lunch time. 


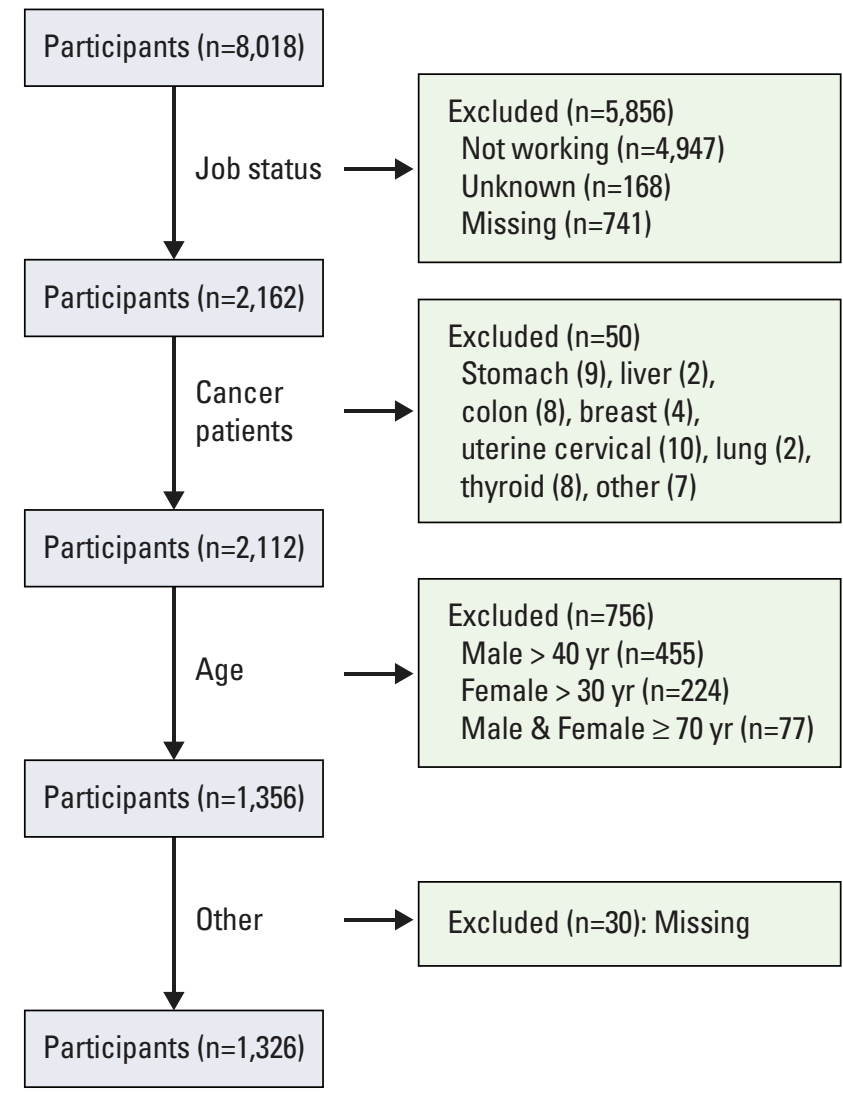

Fig. 1. Flow diagram of the study participants.

\section{Covariates}

We included socioeconomic status such as age, sex, marital status, income, and residential area, which can affect cancer screening [15]. In addition, lifetime smoking, alcohol consumption in the past year, chronic disease, exercise (walking), private insurance, and stress were included as covariates which were suggested as factors associated with cancer screening $[15,16]$. Age was used as a continuous variable, beginning with 30 years old for females and 40 years old for males. Marital status was classified as single or married. Private insurance was classified as participants who had private insurance and those who did not. Stress was measured based on the question: "Do you feel stress from usual life activities?" where stress was classified as those who reported feeling high levels of stress or those who reported feeling a low level of stress. Chronic disease was defined as hypertension or diabetes or dyslipidemia, classified by 'Yes' or 'No.' Alcohol consumption in the past year was classified by 'Yes' or 'No' following the question: "Did you drink alcohol in the past year?" Smoking was classified as smoker (less than five packs, more than five packs) and non-smoker. Exercise was measured by the following question: "Did you walk at least 10 minutes at a time during the past week?" People who did not walk a 10-minute interval in the previous week were classified as 'No.' Income was classified as middle-bottom, middle-top, and top. Residential area was classified according to whether the person lived in a metropolitan area or not.

\section{Statistical analysis}

All analyses were performed using SAS ver. 9.3 (SAS Institute Inc., Cary, NC). Weight was assigned to the sampling results to convey an accurate representation of the entire nation. Baseline demographic and clinical characteristics were compared using chi-squared tests, and $\mathrm{p}<0.05$ was considered statistically significant. Logistic regression analysis was used to calculate the odds ratio (OR) with $95 \%$ confidence intervals $(\mathrm{CI})$ to analyze the association between job status and cancer screening. In the fully adjusted model, all variables were entered simultaneously. In addition, the data were analyzed according to private insurance due to correlation between job status. Although no correlation was observed between job status, sub-group analysis was performed according to different age group. Age was an important variable which can affect cancer screening and different type of cancer screening was provided according to age group [16]. Thus, more evaluation is needed according to different age group. The analysis of stratified data was adjusted for all variables simultaneously.

\section{Results}

\section{Demographics of the study population}

In our study, 869 of the 1,326 wage earners $(65.5 \%)$ who were eligible for this study participated in the cancer screening program. There were 666 full time workers, of whom 448 $(65.3 \%)$ participated, and 660 part time workers, of whom $421(63.7 \%)$ participated. The difference between percentage of screening program participants within the full time and part time worker groups was not significant. According to work type, 733 of 1,123 daytime workers (64.2\%), 60 of 96 nighttime workers $(63.2 \%)$, and 76 of 107 shift workers $(68.8 \%)$ participated in the cancer screening program. Average hours worked during a 1-week period was 39.9 (standard deviation [SD], \pm 15.0 ) for individuals who underwent cancer screening compared to 41.6 (SD, \pm 14.7$)$ for individuals who did not undergo cancer screening. The average age of participants who had undergone cancer screening was 49.4 $(\mathrm{SD}, \pm 9.1)$ years versus $46.5(\mathrm{SD}, \pm 9.6)$ years for those who 
did not $(\mathrm{p}<0.0001)$. According to sex, more female participants $(498 / 743,66.9 \%)$ underwent cancer screening than male participants $(371 / 583,62.2 \%)$. According to insurance, 778 of 1,167 individuals $(66.3 \%)$ who held private insurance underwent cancer screening, while 91 of 159 (51.0\%) who did not hold private insurance underwent cancer screening $(\mathrm{p}=0.0019)$. Regarding residential area, 392 participants $(67.3 \%)$ who lived in metropolitan areas underwent cancer screening, compared to 477 participants $(62.2 \%)$ who did not live in metropolitan areas (Table 1).

\section{Logistic regression analysis for cancer screening}

Part time workers had a lower prevalence of cancer screening compared to full time workers, which was marginally significant (OR, 0.72; CI, 0.53 to 1.00; $\mathrm{p}=0.0495)$. According to work type, a high prevalence of cancer screening was observed for shift workers compared to daytime workers (OR, 1.35; CI, 0.79 to 2.32); however, the difference was not statistically significant. Individuals who spent more time on the job had a lower prevalence of cancer screening than those who worked fewer hours; however, the difference was not statistically significant (OR, 1.00; CI, 0.98 to 1.01; $\mathrm{p}=0.2917$ ). A correlation was observed between increasing age and greater prevalence of cancer screening (OR, 1.04; CI, 1.03 to 1.06; $\mathrm{p}<0.0001)$. According to sex male participants had a lower cancer screening prevalence compared to females (OR, 0.81 ; CI, 0.51 to $1.27 ; \mathrm{p}=0.3525$ ), however the difference was not significant. Single participants had lower cancer screening prevalence compared to married participants (OR, 0.27; CI, 0.14 to $0.51 ; \mathrm{p}<0.0001)$. Participants who did not have private insurance (OR, 0.48 ; $\mathrm{CI}, 0.30$ to $0.77 ; \mathrm{p}=0.0020)$ had a lower prevalence of cancer screening than those who had private insurance. According to residential area, a lower cancer screening prevalence was observed for participants who did not live in metropolitan areas (OR, $0.74 ; \mathrm{CI}, 0.55$ to 0.99 ; $\mathrm{p}=0.0429$ ) (Table 2) than for those who did.

\section{Association between age and cancer screening preva- lence}

The data were further analyzed according to different age groups. As a result, significantly lower prevalence of cancer screening was observed for old part time workers (age, 60 to 69 years) compared with full time workers (OR, 0.27; CI, 0.08 to 0.90 ). Other age group also had lower prevalence of cancer screening, but without statistical significance (Table 3).

\section{Association between private insurance and cancer scre- ening prevalence}

Among part time workers, the prevalence of cancer screen- ing differed according to whether the participant has private insurance or not. High prevalence of cancer screening was observed for part time workers who had private insurance compared with full time workers (OR, 1.13; CI, 0.39 to 3.24); however, the difference was not statistically significant. Part time workers without private insurance had a lower prevalence of cancer screening than full time workers (OR, 0.67; CI, 0.48 to 0.94 ) (Table 3).

\section{Discussion}

In Korea, there is increasing interest in overall health, with a focus on improving health through prevention and early detection of disease. Therefore, in addition to adequate healthcare, individuals can prevent disease or reduce the severity of disease through early detection programs. For example, the Korean government has offered cancer screening free of charge to specific age groups as a cost-effective way of increasing the wellbeing of the population. In general, people believe that cancer can be cured through early detection and treatment; however, many still do not take advantage of cancer screening even though it is provided as a free program. Part time workers (those with unstable work status) are faced with poor working conditions, unfair treatment, and low wages, and often live in a state of anxiety [17], with high risk of morbidity of physical and psychological problems, and had more medical service utilization $[18,19]$. However, they had a lower sick leave rate, working while ill due to concern regarding job insecurity and fear of job loss [20]. This might result in unmet health need, because they have no time for medical utilization, whereas the need for health care was increased. The possibility of unmet need in part time workers might exist in medical service utilization as well as preventive activity.

To explore this problem, we examined whether there is an association between part time workers and prevalence of cancer screening. Almost half of the participants in our study were part time workers. Results of the logistic regression analysis showed that fewer part time workers underwent cancer screening compared to full time workers. Because cancer screening was offered without cost, time could likely be the limiting factor for people who would undergo screening. For example, to undergo cancer screening, workers must request permission from the company they work for in order to take the necessary time away from work. However, because the job status of part time workers is not fixed or stable, these individuals would likely not be able to take time off for cancer screening.

We found an association between increasing age and 
Table 1. Cancer screening percentages, by demographic characteristics

\begin{tabular}{|c|c|c|c|c|}
\hline \multirow{2}{*}{ Variable } & \multicolumn{2}{|c|}{ Cancer screening } & \multirow{2}{*}{ Total $(n=1,326)$} & \multirow{2}{*}{ p-valuc } \\
\hline & Yes & No & & \\
\hline \multicolumn{5}{|l|}{ Job status } \\
\hline Full time worker & $448(65.3)$ & $218(34.7)$ & $666(52.4)$ & 0.6102 \\
\hline Part time worker & $421(63.7)$ & $239(36.3)$ & $660(47.6)$ & \\
\hline \multicolumn{5}{|l|}{ Work type } \\
\hline Day duty & $733(64.2)$ & $390(35.8)$ & $1,123(83.9)$ & 0.6886 \\
\hline Night duty & $60(63.2)$ & $36(36.8)$ & $96(7.2)$ & \\
\hline Shift worker & $76(68.8)$ & $31(31.2)$ & $107(8.9)$ & \\
\hline Hours worked per week & $39.9 \pm 15.0$ & $41.6 \pm 14.7$ & $40.5 \pm 14.9$ & 0.0577 \\
\hline Age & $49.4 \pm 9.1$ & $46.5 \pm 9.6$ & $48.4 \pm 9.4$ & $<0.0001$ \\
\hline \multicolumn{5}{|l|}{ Sex } \\
\hline Male & $371(62.2)$ & $212(37.8)$ & $583(50.4)$ & 0.1476 \\
\hline Female & $498(66.9)$ & $245(33.1)$ & $743(49.6)$ & \\
\hline \multicolumn{5}{|l|}{ Marital status } \\
\hline Single & $18(30.0)$ & $42(70.0)$ & $60(4.3)$ & $<0.0001$ \\
\hline Married & $851(66.1)$ & $415(33.9)$ & $1,266(95.7)$ & \\
\hline \multicolumn{5}{|l|}{ Private insurance } \\
\hline Yes & $778(66.3)$ & $389(33.7)$ & $1,167(88.5)$ & 0.0016 \\
\hline No & $91(51.0)$ & $68(49.0)$ & $159(11.5)$ & \\
\hline \multicolumn{5}{|l|}{ Stress } \\
\hline High & $187(64.0)$ & $101(36.0)$ & $288(22.9)$ & 0.8548 \\
\hline Low & $682(64.7)$ & $356(35.3)$ & $1,038(77.1)$ & \\
\hline \multicolumn{5}{|l|}{ Chronic disease } \\
\hline Yes & $197(72.9)$ & $77(27.1)$ & $274(19.8)$ & 0.0047 \\
\hline No & $672(62.4)$ & $380(37.6)$ & $1,052(80.2)$ & \\
\hline \multicolumn{5}{|c|}{ Alcohol consumption in past year } \\
\hline Yes & $756(63.9)$ & $405(36.1)$ & $1,161(88.8)$ & 0.1938 \\
\hline No & $113(69.4)$ & $52(30.6)$ & $165(11.2)$ & \\
\hline \multicolumn{5}{|l|}{ Smoking } \\
\hline Smoker (under 5 packs) & $17(50.7)$ & $16(49.3)$ & $33(2.8)$ & 0.0050 \\
\hline Smoker (above 5 packs) & $333(59.8)$ & $205(40.2)$ & $538(44.4)$ & \\
\hline Non-smoker & $519(69.2)$ & $236(30.8)$ & $755(52.7)$ & \\
\hline \multicolumn{5}{|l|}{ Exercise } \\
\hline Yes & $751(65.0)$ & $381(35.0)$ & $1,132(85.5)$ & 0.4246 \\
\hline No & $118(61.6)$ & $76(38.4)$ & $194(14.5)$ & \\
\hline \multicolumn{5}{|l|}{ Income } \\
\hline Bottom-middle & $367(57.4)$ & $246(42.6)$ & $613(46.0)$ & 0.0003 \\
\hline Middle-top & $245(71.8)$ & $106(28.2)$ & $351(27.5)$ & \\
\hline Top & $257(69.2)$ & $105(30.8)$ & $362(26.5)$ & \\
\hline \multicolumn{5}{|c|}{ Residential area, metropolitan } \\
\hline Yes & $392(67.3)$ & $182(32.7)$ & $574(45.7)$ & 0.1096 \\
\hline No & $477(62.2)$ & $275(37.8)$ & $752(54.3)$ & \\
\hline Total & $869(64.5)$ & $457(35.5)$ & $1,326(100)$ & \\
\hline
\end{tabular}

Values are presented as number $(\%)$ or mean \pm standard deviation.

increased prevalence of cancer screening, which was likely due to increased interest in health as one grows older. According to marital status and private insurance, a lower cancer screening prevalence was observed for single people and those who did not have private insurance. We speculate that single participants tended to be neglectful of self-health care in general as a reason for not undergoing cancer screening. 
Table 2. Logistic regression model of cancer screening

\begin{tabular}{|c|c|c|c|}
\hline Variable & OR & $95 \%$ CI & p-value \\
\hline \multicolumn{4}{|l|}{ Job status } \\
\hline Full time worker & Reference & - & 0.0495 \\
\hline Part time worker & 0.72 & $0.53-1.00$ & \\
\hline \multicolumn{4}{|l|}{ Work type } \\
\hline Day duty & Reference & - & 0.5535 \\
\hline Night duty & 1.01 & $0.62-1.65$ & \\
\hline Shift worker & 1.35 & $0.79-2.32$ & \\
\hline Hours worked per week & 1.00 & $0.98-1.01$ & 0.2917 \\
\hline Age & 1.04 & $1.03-1.06$ & $<0.0001$ \\
\hline \multicolumn{4}{|l|}{ Sex } \\
\hline Male & 0.81 & $0.51-1.27$ & 0.3525 \\
\hline Female & Reference & - & \\
\hline \multicolumn{4}{|l|}{ Marital status } \\
\hline Single & 0.27 & $0.14-0.51$ & $<0.0001$ \\
\hline Married & Reference & - & \\
\hline \multicolumn{4}{|l|}{ Private insurance } \\
\hline Yes & Reference & - & 0.0020 \\
\hline No & 0.48 & $0.30-0.77$ & \\
\hline \multicolumn{4}{|l|}{ Stress } \\
\hline High & 1.18 & $0.85-1.65$ & 0.3235 \\
\hline Low & Reference & - & \\
\hline \multicolumn{4}{|l|}{ Chronic disease } \\
\hline Yes & 1.45 & $1.01-2.09$ & 0.0452 \\
\hline No & Reference & - & \\
\hline \multicolumn{4}{|c|}{ Alcohol consumption in past year } \\
\hline Yes & 0.78 & $0.53-1.16$ & 0.2214 \\
\hline No & Reference & - & \\
\hline \multicolumn{4}{|l|}{ Smoking } \\
\hline Smoker (under 5 packs) & 0.44 & $0.16-1.21$ & 0.0306 \\
\hline Smoker (above 5 packs) & 0.62 & $0.41-0.94$ & \\
\hline Non-smoker & Reference & - & \\
\hline \multicolumn{4}{|l|}{ Exercise } \\
\hline Yes & 1.14 & $0.77-1.69$ & 0.5190 \\
\hline No & Reference & - & \\
\hline \multicolumn{4}{|l|}{ Income } \\
\hline Bottom-middle & 0.62 & $0.43-0.90$ & 0.0033 \\
\hline Middle-top & 1.12 & $0.75-1.67$ & \\
\hline Top & Reference & - & \\
\hline \multicolumn{4}{|c|}{ Residential area, metropolitan } \\
\hline Yes & Reference & - & 0.0429 \\
\hline No & 0.74 & $0.55-0.99$ & \\
\hline
\end{tabular}

OR, Odds ratio; CI, Confidence interval.

In addition, a lower cancer screening prevalence was observed for individuals who did not have private insurance. In Korea, individuals can voluntarily enroll in a private insurance program to supplement their national health insurance. Private insurance covers additional costs not paid by the National Health Insurance (NHI) system. Private insurance enrollment might be associated with health consciousness, because the individuals are choosing to reduce unexpected health expenditures. People with high health consciousness may be more likely to have private insurance, which would be associated with engaging in preventative healthcare, such as cancer screening [21]. 
Table 3. Sub-group analysis of cancer screening according to different age group and private insurance ${ }^{\text {a) }}$

\begin{tabular}{|c|c|c|c|}
\hline Variable & OR & $95 \% \mathrm{CI}$ & p-value \\
\hline \multicolumn{4}{|l|}{ Age (yr) } \\
\hline$<40$ & 0.71 & $0.28-1.78$ & 0.4629 \\
\hline $40-49$ & 0.77 & $0.44-1.34$ & 0.3513 \\
\hline $50-59$ & 0.66 & $0.36-1.22$ & 0.1839 \\
\hline 60-69 & 0.27 & $0.08-0.90$ & 0.0327 \\
\hline \multicolumn{4}{|c|}{ Private insurance } \\
\hline Yes & 1.13 & $0.39-3.24$ & 0.8209 \\
\hline No & 0.67 & $0.48-0.94$ & 0.0214 \\
\hline
\end{tabular}

$\mathrm{OR}$, odds ratio; $\mathrm{CI}$, confidence interval. ${ }^{\text {a) }}$ The association between cancer screening and part time workers was compared to that of full time workers; all variables are adjusted for: hours worked per week, age, sex, marital status, private insurance, stress, chronic disease, alcohol consumption in previous year, smoking, exercise, income, and residential area.

In our sub-group analysis, private insurance showed significant association with cancer screening. A lower prevalence of cancer screening was observed for part time workers without private insurance. These results suggest that private insurance may be important for part time workers. Private insurance might serve as a supplementary health resource for part-time workers who are vulnerable to preventable diseases.

In our study, low income participants had lower prevalence of cancer screening, similar to previous studies [22]. This might be due to increased concerns related to the health expenditure by low income participants, which might affect preventive activity such as cancer screening.

Cancer screening prevalence also showed a decreasing trend with increasing age for part time workers; however, statistical significance was only observed in the 60- to 69year-old group. Logically, the 60- to 69-year-old group should be more focused on their health than other age groups. However, due to their unstable position in the company, part time workers may feel pressured to work harder and take less time for healthcare. Therefore, these individuals might not focus on their own healthcare, including cancer screening, making them more vulnerable to preventable diseases when they are employed as a part time worker.

Our study was similar to previous studies which suggested that job insecurity can negatively impact psychological health and self-rated health $[17,19,23]$. In addition, job insecurity was associated with a higher prevalence of physical health problems, such as asthma and coronary heart disease [24,25]. However, few studies on the association between job insecurity and cancer screening in Korea have been reported. Furthermore, this is the first investigation that considered factors such as where workers live and work shift and why part time workers are less likely than full time workers to participate in cancer screening programs. Thus, our findings will be helpful to understanding the conditions faced by part time workers that impact their overall health.

Our study had several limitations. First, this study had a cross-sectional design; therefore, a causal relationship between cancer screening and job status could not be definitively determined. Second, we did not consider personal health management, which can affect cancer screening prevalence because people interested in personal health would be more likely to visit the hospital to undergo cancer screening. Finally, information on family history was not collected, which can affect whether or not a person seeks cancer screening. Further studies are needed in order to better understand the association between cancer screening and job status.

Despite these limitations, our study had a number of strengths. First, we used data from the KNHANES in 2013, which ensured that a reliable, large scale sampling design that encompassed and was representative of the entire country was used. Second, to the best of our knowledge, this study was the first to focus on cancer screening and part time workers who face invisible discrimination in the workplace. Third, our study examined factors related to health in the workplace, and revealed vulnerabilities in health care that arise as a result of job insecurity.

Currently, relative discrimination has become a major issue in South Korea. This may be due to one's personal position in the company as well as interrelationships; it affects people who are in lower positions relative to the general population. Such discrimination is present in the workplace. Part time workers feel stress and anxiety due to their position, and have concern about their wages. Because of these insecurities, part time workers are unable to take part in basic preventive activities that are available to others, such as full time workers. The increasing incidence of cancer supports an increase in cancer screening for early detection and treatment; however, the job status of part time workers 
clearly influences their health management. To solve this problem, companies should better accommodate the needs of part time workers, making it easier for them to manage their health. In addition, health campaigns and positive assistance by companies will be helpful to part time workers in the effort to improve their health.

\section{Conflicts of Interest}

Conflict of interest relevant to this article was not reported.

\section{Conclusion}

In conclusion, we determined that part time workers, who often face relative discrimination, are less able to participate in programs focused on prevention of disease. Solving the problems of anxiety and job instability experienced by part time workers is difficult, although it may be possible to improve health through ensuring participation in prevention programs. Such an effort will involve changes in social care and the workplace atmosphere.

\section{Acknowledgments}

This study was supported by a grant from the National R\&D Program for Cancer Control, Ministry of Health and Welfare, Republic of Korea (No. 1420230). The funding source had no role in the design and conduct of the study; collection, management, analysis, and interpretation of the data; and preparation, review or approval of the manuscript.

\section{References}

1. Ferlay J, Soerjomataram I, Dikshit R, Eser S, Mathers C, Rebelo $\mathrm{M}$, et al. Cancer incidence and mortality worldwide: sources, methods and major patterns in GLOBOCAN 2012. Int J Cancer. 2015;136:E359-86.

2. Pyenson BS, Sander MS, Jiang Y, Kahn H, Mulshine JL. An actuarial analysis shows that offering lung cancer screening as an insurance benefit would save lives at relatively low cost. Health Aff (Millwood). 2012;31:770-9.

3. Paci E, Broeders M, Hofvind S, Puliti D, Duffy SW; EUROSCREEN Working Group. European breast cancer service screening outcomes: a first balance sheet of the benefits and harms. Cancer Epidemiol Biomarkers Prev. 2014;23:1159-63.

4. van Schoor G, Moss SM, Otten JD, Donders R, Paap E, den Heeten GJ, et al. Increasingly strong reduction in breast cancer mortality due to screening. Br J Cancer. 2011;104:910-4.

5. Schoen RE, Pinsky PF, Weissfeld JL, Yokochi LA, Church T, Laiyemo AO, et al. Colorectal-cancer incidence and mortality with screening flexible sigmoidoscopy. N Engl J Med. 2012; 366:2345-57.

6. Statistics Korea. Cancer mortality. Daejeon: Statistics Korea; 2014.

7. Yoo KY. Cancer control activities in the Republic of Korea. Jpn J Clin Oncol. 2008;38:327-33.

8. Kim Y, Jun JK, Choi KS, Lee HY, Park EC. Overview of the National Cancer screening programme and the cancer screening status in Korea. Asian Pac J Cancer Prev. 2011;12:725-30.

9. National Cancer Center. Cancer Facts \& Figures 2013. Goyang: National Cancer Center; 2013.
10. Kim IH, Muntaner C, Vahid Shahidi F, Vives A, Vanroelen C, Benach J. Welfare states, flexible employment, and health: a critical review. Health Policy. 2012;104:99-127.

11. Naswall K, Lindfors P, Sverke M. Job insecurity as a predictor of physiological indicators of health in healthy working women: an extension of previous research. Stress Health. 2012;28:255-63.

12. Kirves K, De Cuyper N, Kinnunen U, Natti J. Perceived job insecurity and perceived employability in relation to temporary and permanent workers' psychological symptoms: a two samples study. Int Arch Occup Environ Health. 2011;84: 899-909.

13. Olesen SC, Butterworth P, Jacomb P, Tait RJ. Personal factors influence use of cervical cancer screening services: epidemiological survey and linked administrative data address the limitations of previous research. BMC Health Serv Res. 2012; $12: 34$.

14. Ho MY, Lai JY, Cheung WY. The influence of physicians on colorectal cancer screening behavior. Cancer Causes Control. 2011;22:1659-68.

15. Yeo JY, Jeong HS. Determinants of health screening and its effects on health behaviors. Korean J Health Policy Adm. 2012;22:49-64.

16. Kim MK, Nam EW, Jin KN. The factors influencing the odds of cancer examination in Wonju city. Korean J Health Educ Promot. 2006;23:85-97.

17. Ferrie JE, Shipley MJ, Newman K, Stansfeld SA, Marmot M. Self-reported job insecurity and health in the Whitehall II 
study: potential explanations of the relationship. Soc Sci Med. 2005;60:1593-602.

18. Virtanen M, Kivimaki M, Joensuu M, Virtanen P, Elovainio M, Vahtera J. Temporary employment and health: a review. Int J Epidemiol. 2005;34:610-22.

19. Caroli E, Godard M. Does job insecurity deteriorate health? Health Econ. 2016;25:131-47.

20. Ferrie JE. Is job insecurity harmful to health? J R Soc Med. 2001;94:71-6.

21. Ray-Mazumder S. Role of gender, insurance status and culture in attitudes and health behavior in a US Chinese student population. Ethn Health. 2001;6:197-209.

22. Coughlin SS, Leadbetter S, Richards T, Sabatino SA. Contextual analysis of breast and cervical cancer screening and fac- tors associated with health care access among United States women, 2002. Soc Sci Med. 2008;66:260-75.

23. Waenerlund AK, Virtanen P, Hammarstrom A. Is temporary employment related to health status? Analysis of the Northern Swedish Cohort. Scand J Public Health. 2011;39:533-9.

24. Loerbroks A, Bosch JA, Douwes J, Angerer P, Li J. Job insecurity is associated with adult asthma in Germany during Europe's recent economic crisis: a prospective cohort study. J Epidemiol Community Health. 2014;68:1196-9.

25. Ferrie JE, Kivimaki M, Shipley MJ, Davey Smith G, Virtanen M. Job insecurity and incident coronary heart disease: the Whitehall II prospective cohort study. Atherosclerosis. 2013;227:178-81. 